\title{
Invitation for University Programs to Apply for Accreditation by the ERM Institute International (ERM-II)
}

ERM Institute International (ERM-II) is a non-profit educational and research organization, initiated by an international group of universities and professional organizations with a focus on education, research, and training within an Enterprise Risk Management (ERM) conceptual framework, quantitative methods and tools, and best practices.

More information about ERM-II is available from: http://www.ermii.org and about its educational objectives at http://www.ermii.org/Education/Educ_ ndx.html

The standards for university program accreditation of ERM-II are founded on the premise of improving the competence of those entering the risk management profession by ensuring a minimum level of technical competence and enough breadth across the mathematical, economic and statistical tools required to conduct sound quantitative risk analysis as applied in a range of industries.

University accreditation requirements cover program content, study requirements, entry requirements, course instructors, and research program. The details are available for the University Program Requirements at

\section{http://www.ermii.org/Education/Acc_Reqs.htm}

ERM-II is inviting graduate-level university programs in financial engineering and quantitative risk management to apply for accreditation. Applications should include the following information: reasons for applying for accreditation, brief background of the university and program, how the program meets the accreditation requirements, program academic structure, course descriptions and course guides, entry requirements, brief $\mathrm{CV}$ and publications for academic staff, research program information, research grant funding, working papers and publications for previous 5 years, program testimonials from industry or professional associations.

Applications should be submitted to the University Accreditation Committee for ERM-II preferably in electronic format by email.

\section{Please send inquiries and applications to:}

Amy Aldous (aaldous@uwaterloo.ca)

Institute for Quantitative Finance and Insurance

University of Waterloo, Waterloo ON N2L 3G1 Canada

Further information available from the Chair, University Accreditation Committee, Professor Michael Sherris, Faculty of Commerce and Economics, UNSW (m.sherris@unsw.edu.au) 